Arantes, E.C.; Araújo, S.B.; Ferko, G.P.S.; Nogueira, E.M. Potencialidades do ecoturismo na Serra do Tepequém (RR) sob múltiplos olhares. Anais do IX Congresso Nacional de Ecoturismo e do V Encontro Interdisciplinar de Turismo em Unidades de Conservação. Revista Brasileira de Ecoturismo, São Paulo, v.6, n.4, nov-2013, pp.83-102.

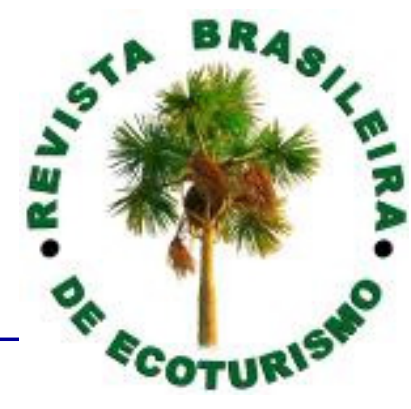

\title{
Potencialidades do ecoturismo na Serra do Tepequém (RR) sob múltiplos olhares
}

\author{
Potential of ecotourism in the Serra do Tepequém (RR, Brazil) under multiple \\ perspectives
}

\author{
Emerson Clayton Arantes, Simone Briglia de Araújo, \\ Georgia Patrícia da Silva Ferko, Elizabete Melo Nogueira
}

\section{RESUMO}

Este trabalho apresenta potencialidades do desenvolvimento do turismo na Serra do Tepequém, localizada no Estado de Roraima, bem como a percepção de moradores, visitantes, e empresários de pousadas sobre o ecoturismo praticado na região. A partir da análise do referencial teórico sobre o assunto, pretendeu-se diagnosticar e prognosticar propostas para esse setor. Quanto aos procedimentos metodológicos, recorreu-se à pesquisa exploratória e descritiva. $\mathrm{O}$ aspecto lógico se caracterizou pelo dedutivo, enquanto que a abordagem se deu pelo modelo quali-quanti. Para a coleta dos dados, foram utilizados questionários, aplicados aos moradores, visitantes e entrevistas aos empresários de pousada. Os resultados obtidos refletiram a realidade do ecoturismo que se apresenta atualmente na região, que apesar de não dispor de infraestrutura condizente, consegue atrair visitantes, que ficam satisfeitos. Os empresários e os residentes acreditam que existe um grande potencial para incrementar ecoturismo na região, em função da demanda premente e dos atrativos naturais existentes.

PALAVRAS-CHAVE: Turismo; Ecoturismo; Atrativos; Natureza; Tepequém.

\begin{abstract}
This paper presents the tourism development potential in the Serra do Tepequém (RR,Brazil), and the perceptions of residents, visitors, and inns owners about the ecoturism practiced in the region. From the theoretical analysis on the subject, intended to diagnose and predict proposals for this sector. Regarding methodological procedures, recourse to the research was exploratory and descriptive. The logical appearance was characterized by the deductive approach while the model was the qualitative and quantitative. For data collection, we have used questionnaires administered to residents, visitors and interviews with inns owners. The results reflected the reality of ecotourism that currently appears in the region, although it lacks infrastructure befitting, manages to attract visitors who are satisfied. The entrepreneurs and residents believe that there is great potential to increase ecotourism in that region, due to permanent demand and attractive nature that exists there.
\end{abstract}

KEYWORDS: Tourism; Ecoturism; Attractive; Nature; Tepequém. 


\section{Introdução}

No Brasil, a inserção do ecoturismo se deu no final da década de 80, acompanhando a tendência internacional. Nesse ensejo, em 1989, a Empresa Brasileira de Turismo - EMBRATUR - autorizou os primeiros cursos de guia direcionados a esse tipo de turismo. Em 1992, com a realização da Conferência das Nações Unidas sobre o Meio Ambiente e o Desenvolvimento - CNUMAD - conhecida também como Rio-92, o termo ecoturismo alcançou maior evidência, agradou ao público e estimulou um mercado promissor, que desse momento em diante não parou mais de crescer. Posteriormente a esse evento, órgãos e instituições ligadas ao segmento foram sendo criados para fornecer o apoio necessário que a atividade requer.

Quando se compara o Brasil com a Europa, em termos de desenvolvimento ecoturístico, é verificado que se está bastante distante do desejado. A Europa e os EUA já possuem um trabalho bem mais avançado, permitindo que figurem entre os primeiros da lista, em termos de visitação. Outro exemplo ocorre com a Costa Rica, que recebe aproximadamente 600 mil visitantes por ano, enquanto a Amazônia atrai apenas cerca de 50 mil.

No Estado de Roraima, a região da Serra do Tepequém ficou conhecida na década de 1930, por ter sido um local de grande exploração mineral, em especial, do diamante. Durante anos, essa foi a atividade principal praticada na região, que gradativamente foi sendo substituída pela pecuária bovina. Hoje, essa atividade de garimpo figura apenas em relatos de antigos moradores, ou ainda quando aparece um garimpeiro remanescente na esperança de encontrar alguma riqueza.

Embora a região tenha a pecuária extensiva como uma das principais atividades econômicas, a região possui um expoente natural suficiente para ofertar o ecoturismo que, se bem utilizado, pode impulsionar micros e pequenos negócios; geração de emprego local; fixação da população no interior; melhorias no saneamento; alternativas de arrecadação municipal, dentre outros benefícios.

Ensejado por essas alternativas possíveis de proporcionar melhorias a uma determinada localidade, o presente trabalho teve como objetivo geral descobrir qual a percepção da comunidade sobre o ecoturismo, bem como identificar atividades que podem ser desenvolvidas em conformidade com os preceitos desse serviço.

O aspecto lógico da pesquisa se caracteriza pelo dedutivo, enquanto que a abordagem se deu pelo modelo quali-quanti. O horizonte-temporal foi inteiramente evidenciado pelo transversal, dando preferência para informações atuais sobre o tem. $\mathrm{Na}$ coleta dos dados, foram utilizados questionários aplicados junto a 86 (oitenta e seis) moradores, 40 (quarenta) visitantes e 4 (quatro) empresas (pousadas), perfazendo um total de 140 respondentes.

Acredita-se que estudo pode auxiliar na construção de parâmetros e possíveis linhas de conduta com vistas ao correto desenvolvimento, implantação e funcionamento do ecoturismo de forma a assumirem ações ambientais e sociais. Que as ações propostas venham beneficiar todos os atores envolvidos, tanto a 
comunidade do entorno como os grupos empreendedores.

Este trabalho está divido em seções, sendo a primeira a revisão de literatura do ecoturismo como uma prática mundial, bem como suas proposições. Seguidamente, na segunda seção faz-se a caracterização do Município de Amajari, dando ênfase aos seus aspectos físicos geográficos. Na terceira seção, apresentam-se os resultados sobre o ecoturismo pela ótica dos empresários de pousada, moradores, e visitantes, bem como as potencialidades ecoturísticas, apontando as atividades que podem ser praticadas na região da Serra do Tepequém. Na última, manifestam-se as considerações finais, sucedidas das referências.

\section{O ecoturismo como uma prática mundial}

O termo ecoturismo surgiu no meio acadêmico no final da década de 1970, quando começaram a ser divulgados com maior intensidade os vídeos e documentários sobre viagens que tinham como cenário a natureza, com o intuito de promover o turismo ecológico no mundo.

A partir daí, as regiões mais longínquas, que dispunham de aptidões naturais para o incremento das atividades ecoturísticas, começaram a fomentar a ideia principal que alicerça o ecoturismo, ou seja, a valorização das premissas ambientais, sociais, culturais e econômicas.

De acordo com Western (1995), o ecoturismo explodiu no mundo das viagens e da conservação como uma espécie de tsunami, um verdadeiro maremoto; porém, suas origens são definitivamente mais evolutivas que revolucionárias. As raízes do ecoturismo encontram-se na natureza e no turismo ao ar livre.

Os primeiros visitantes considerados como ecoturistas foram os que, há pouco mais de um século, chegaram em massa aos parques nacionais de Yellowstone e Yosemite, vindo em seguida os visitantes pioneiros do Serengeti, os aventureiros caminhantes do Himalaia e, mais recentemente, os milhares de ecoturistas que fotografam pinguins na Antártida.

Ao longo do século $X X$, foi possível assistir a várias mudanças com relação às viagens a áreas naturais. Um exemplo é o que ocorria anteriormente na África, onde o safári de caça era notadamente uma atividade fortemente desenvolvida na região. Aos poucos, foram perdendo lugar para novos modelos de turismo, onde a preocupação com o ambiente e com os seres que nele habitam se tornaram mais importantes devido à amplitude da consciência aos danos até então praticados.

Neto (2007) destaca que a primeira utilização do termo ecoturismo é, frequentemente, apontada a Lascuráin (1998). Mas Dias (2003) chama a atenção para o fato de que o primeiro a utilizar o termo tenha sido, de fato, Hertzer (1965), que apresentou as primeiras ideias sobre turismo e desenvolvimento, propondo fazer dele um instrumento útil para o ecodesenvolvimento, no momento em que a crise ambiental emergia.

De acordo com Campos (2005, p.3), "o ecoturismo é uma nova concepção de turismo que supera as práticas convencionais". Segundo esse autor, essa modalidade 
de turismo é nova, pois apresenta características de conservação do meio ambiente; e educacional, na medida em que o turista tem respeito pelo espaço visitado.

No mesmo sentido, Faria (2012) define Ecoturismo como:

O turismo planejado que promove a interação entre natureza e comunidade com vistas a uma utilização sustentável e conservacionista do patrimônio natural e cultural, proporcionando melhoria na qualidade de vida da população envolvida sem causar impactos negativos à sua territorialidade (FARIA, 2012, p 57).

Acerca das definições, Faria (2012) afirma que para designar ecoturismo, surgem diversas denominações como turismo sustentável, turismo responsável, turismo alternativo e ainda turismo ecológico. Essas definições direcionam o ecoturismo como um tipo de turismo, tendo como principal atrativo a natureza, envolvendo o patrimônio e atrativo cultural em algumas conceituações.

A Sociedade Internacional de Ecoturismo (The InternationalEcoturismSociety - TIES) denota que essa atividade designa um envolvimento sério com a natureza e com a responsabilidade social, além dos próprios viajantes ou visitantes, surgindo dessa forma a expressão viagem responsável (MUNHOZ, 2010).

Nesse sentido, o ecoturismo está pautado em cumprir papéis importantes, como a questão da educação ambiental e a integração das comunidades locais no planejamento e gestão da atividade, além do comprometimento do uso racional dos recursos disponíveis. O turismo responsável é para Hertzer (1965 apud NETO, 2007), embasado nos seguintes moldes:

- Mínimo impacto ambiental;

- Mínimo impacto sobre - e o máximo respeito pelas comunidades locais;

- Máximo benefício econômico para os países anfitriões; e

- Máxima satisfação recreacional para os turistas.

Dessa forma, percebe-se que a concepção de ecoturismo por Hertzer(1965) busca preservar o meio ambiente e promover a satisfação de uma elite amante da natureza. Na verdade, conforme descrito por Western (1995), chega a ser um conjunto de interesses que se manifestam nas preocupações de ordem ambiental, econômica e social.

No que tange às preocupações de ordem ambiental, o ecoturismo alcançou maior notoriedade na Conferência das Nações Unidas, a chamada Rio-92, onde o tema principal foi o meio ambiente. A partir desse momento o ecoturismo, em especial no Brasil, passou a ser visto como uma ferramenta capaz de trazer benefícios à natureza e à sociedade, ou seja, fazer uso do ambiente de maneira planejada e responsável, aliado à melhoria de condições de vida para as comunidades locais. 
Estudos realizados e disponibilizados em Brasil (2007) ressaltam que para uma prática turística ser entendida como ecoturística, é necessário oferecer ações para que o turista seja informado e sensibilizado para a conservação e importância das áreas visitadas.

Nesse aspecto, é primordial que os locais onde as atividades ecoturísticas são desenvolvidas tenham pessoas capacitadas para fornecer informações e auxiliar os visitantes do local da melhor maneira possível, tanto no quesito relativo às práticas que podem ser desenvolvidas no local, como esclarecimentos quanto ao uso correto do ambiente como um todo.

No que tange aos diferenciais do ecoturismo em meio ao segmento turístico, Pires (2005 apud HINTZE, 2008) considera o atendimento a pequenos grupos de até 25 pessoas, a utilização de meios de hospedagem com menos de 100 leitos; operações com empresas de pequeno e médio porte, concentrando-se na condução e na acomodação de pequenos grupos para oferecer atendimento personalizado, com uso de materiais interpretativos e guias especializados, além da preocupação com a capacitação e o treinamento de guias, operadores e fornecedores de serviços requeridos pela atividade.

Como a atividade ecoturística depende da conservação dos recursos da área natural, acredita-se que possa haver uma parceria natural entre empresas privadas que organizam experiências de viagem pela natureza e os atores (governos, entidades não-governamentais e privadas) responsáveis pela proteção das áreas naturais. Nesse aspecto, pode-se esperar que, no caso de essa perspectiva se cristalizar, seja possível imaginar uma verdadeira experiência ecoturística, permitindo a difusão da consciência ambiental a um público bem maior, além de provisão de recursos econômicos para a comunidade local que permitam maximizar seu desenvolvimento.

Para Azevedo (2007), os elementos que fazem parte desse tipo de turismo são sustentabilidade, natureza e cultura, que se interrelacionam de uma maneira singular na Amazônia. Isso só vem confirmar o potencial do ecoturismo no Estado de Roraima, onde essa atividade, que pode ser diversificada, ainda é pouco explorada.

Todavia, Faria (2012, p. 57) ressalta que para desenvolver o ecoturismo é necessário levar em consideração alguns princípios básicos:

- O Atrativo ecoturístico deve envolver o patrimônio natural e cultural utilizado de forma integrada;

- Utilização sustentável e conservacionista dos atrativos;

- Envolvimento da comunidade (planejamento e gestão participativa e comunitária das atividades ecoturísticas);

- Forma ideal de funcionamento em pequenos grupos respeitando a capacidade de carga e de suporte;

- Valorização (formação e capacitação) dos recursos humanos locais;

- Conservação e valorização das atividades tradicionais do lugar e 
- Respeito à identidade cultural e territorial do lugar.

Dessa maneira, o ecoturismo pode ser uma forma de valorizar e conservar as atividades tradicionais das comunidades locais e gerar o desenvolvimento, especialmente na Serra do Tepequém.

\section{Metodologia}

Para Gil (2010), a pesquisa pode ser requerida quando não se dispõe de informações suficientes para responder ao problema, ou então quando a informação disponível se encontra em tal estado de desordem que não possa ser adequadamente relacionada ao problema.

Desse modo, a metodologia utilizada no presente estudo buscou sustentação na classificação dos objetivos mais gerais em pesquisa exploratória, que Gil (2010) descreve como sendo aquela que é realizada quando o tema escolhido é pouco explorado, tornando difícil se formular hipóteses precisas a respeito.

A linha filosófica teve bases positivistas, que segundo Barros, Lehfeld (2009), se trata do tipo de pesquisa na qual se realiza a observação dos dados da experiência, das leis que regem o fenômeno. Para esta linha filosófica, todo conhecimento humano origina-se direta ou indiretamente da experiência, e para tal constatação, se realizou uma visita à região da Serra do Tepequém, no mês de outubro de 2011.

No que tange ao aspecto lógico, o modelo a ser utilizado se caracterizou pelo dedutivo que, segundo Lakatos e Marconi, (2010, p.72), "reformula ou enuncia de modo explícito uma informação já contida em premissas". Assim, se partiu da análise de modelos já pré-concebidos de atividade ecoturística no caso em questão, onde se buscou elementos já existentes com relação a ele.

A abordagem aplicada se deu por meio do modelo quali-quanti. No primeiro momento, apresentando-se de forma qualitativa, que conforme Richardson et al. (1999), diz-se do tipo de pesquisa caracterizada pela tentativa de uma compreensão detalhada dos significados e características situacionais apresentadas pelos entrevistados. Foram entrevistados os empresários das pousadas.

Em um segundo momento, a abordagem se materializou sob o viés quantitativo, pois como novamente descrito por Richardson et al. (1999), o método quantitativo se dá pelo emprego da quantificação tanto nas modalidades de coleta de informações quanto no tratamento delas, por meio de técnicas estatísticas, das mais simples às mais complexas. No presente estudo, para se obter as informações no modelo quantitativo, foi utilizado um questionário de Hanai (2009), o qual foi adaptado segundo as necessidades da pesquisa.

Para se calcular a amostra necessária de questionários para aos moradores, levou-se em consideração a população urbana de 1.219 habitantes, conforme dados da Sinopse do Censo/IBGE/2010. Desse modo, levou-se em conta o erro amostral de $9 \%$, que conforme exposto por Santos (2011), é a diferença entre o valor estimado 
pela pesquisa e o verdadeiro valor, além do nível de confiança no valor de $90 \%$, que exprime a probabilidade de que o erro amostral efetivo seja menor do que o erro amostral admitido pela pesquisa. Os cálculos foram realizados online, em sítio denominado cálculo amostral. Como resultado da amostra necessária, se precisaria aplicar 79 questionários para a pesquisa, no entanto foi possível atingir 86 respondentes, excedendo o que seria indispensável.

Quanto ao empresários de pousadas, devido à época de em que se desenvolveu o trabalho, só foram possíveis 04 respondentes, do total de 06 . 0 número de visitantes atingiu um total de 40 respondentes.

\section{Caracterização do ecoturismo na Serra do Tepequém no município de Amajari}

O Brasil, conhecido mundialmente por suas belezas naturais e "exotismo", atrai demanda interna e externa, em especial para áreas de difícil acesso, a exemplo: a região central do País, as áreas do sertão, e regiões pouco habitadas como Pantanal e Amazônia.

No caso da Amazônia, têm-se o Estado de Roraima, localizado ao norte do País, fazendo fronteira com a Guiana e Venezuela e que é conhecido pela biodiversidade de sua flora e fauna. As cachoeiras, corredeiras, serras, zonas de mata e savanas recortadas por rios de águas transparentes denotam o potencial do estado para o Ecoturismo, sendo, portanto, uma boa alternativa para os amantes da natureza.

Conforme informações do Instituto Brasileiro de Geografia e Estatística- IBGE, o município de Amajari está localizado ao norte do Estado de Roraima, na mesorregião Norte, microrregião Boa Vista, situado nas coordenadas geográficas 61 '25'15' de longitude Oeste e $03^{\circ} 39^{\prime} 19^{\prime}$ de latitude Norte. Limita-se ao norte com Venezuela e com o município de Pacaraima; ao Sul com o município de Alto Alegre e Boa Vista; a Leste com o município de Pacaraima e Boa Vista, a Oeste com a República Bolivariana da Venezuela.

O roteiro integrado da rota $174 \mathrm{AM} / \mathrm{RR}$ tem início em Manaus no Estado do Amazonas e percorre toda extensão da BR-174 até Pacaraíma, município do Estado de Roraima, que faz fronteira com a Venezuela (Figura 1). Durante o trajeto, está inserido nessa rota o município de Amajari/RR, onde se localiza a Serra do Tepequém, uma elevação em forma de Tepuí, ou seja, com paredes retas, de até 1000 metros, e topo achatado.

A Serra do Tepequém se dá pelo Município de Amajari, ficando à 40 quilômetros da sede do município e a $250 \mathrm{~km}$ da capital Boa Vista. A região é conhecida por ser palco do garimpo de pedras preciosas entre as décadas de 30 e 70 do século passado. O topo da Serra é um imenso vale, atravessado pelos rios Sobral e Paiva.

No caminho para a serra, a paisagem vai mudando a cada quilômetro rodado. O cerrado e os igarapés que lembram o Pantanal vão, aos poucos, cedendo lugar à mata fechada. Numa visita é possível conhecer a geologia, formas primitivas de mineração, impactos ambientais provocados pelo garimpo e algumas cachoeiras. 


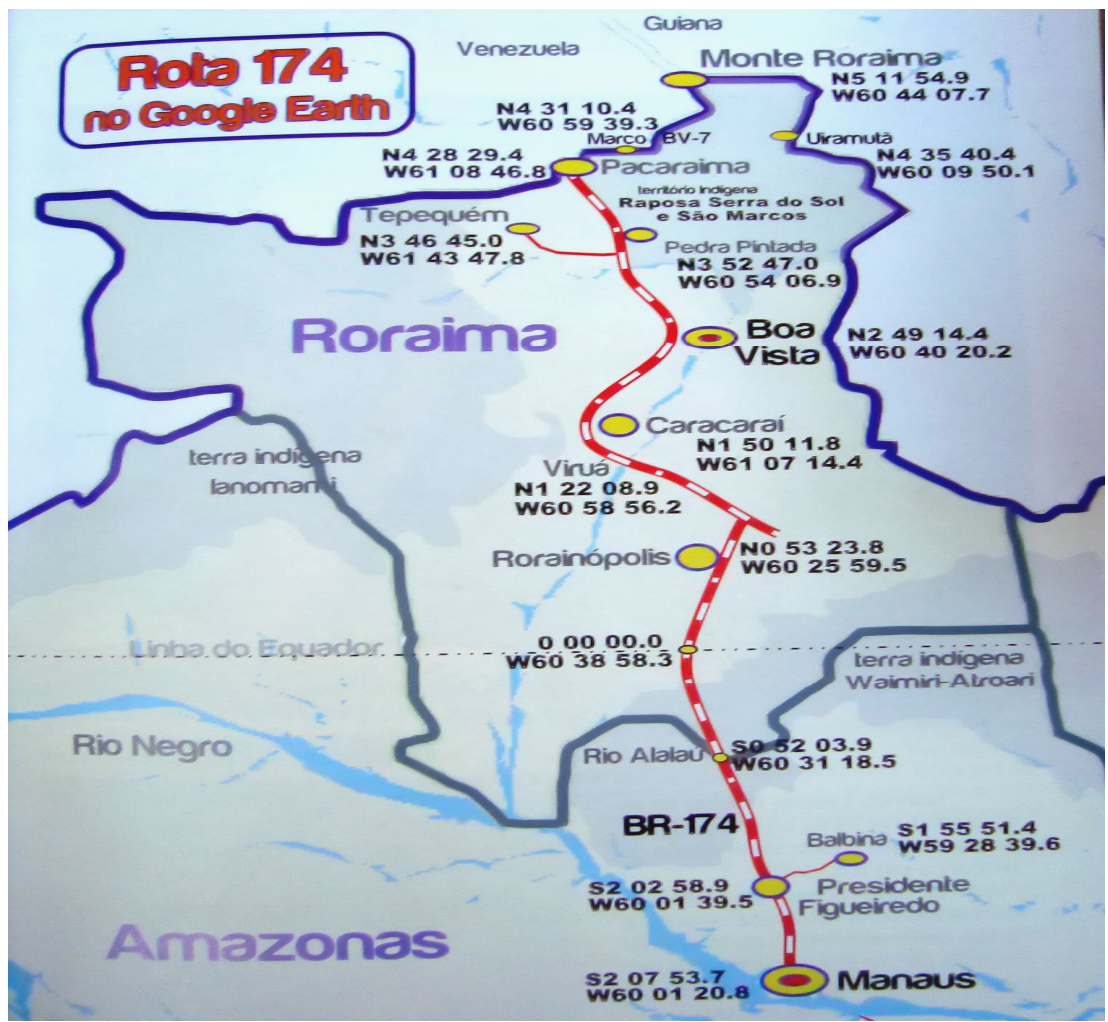

Figura 1: Mapa Rota 174. Figure 1: Map of Rota 174.

Fonte: Revista Rota dos 15 pontos (2010). Source: Revista Rota dos 15 pontos (2010).

De acordo com Bezerra Neta et al. (2007), a paisagem regional que compõe as áreas de entorno da serra do Tepequém (Figura 2) é caracterizada por uma diversificação de formas de relevo, sendo distinguida por uma estrutura de relevo tabular, compondo um testemunho isolado do Planalto Sedimentar Roraima, e em seu topo, por uma área aplainada denominada de planície e intermontana, que tem altitudes que variam entre 575 a 670 metros e está encaixada entre morros residuais e as encostas íngremes (Figura 3).

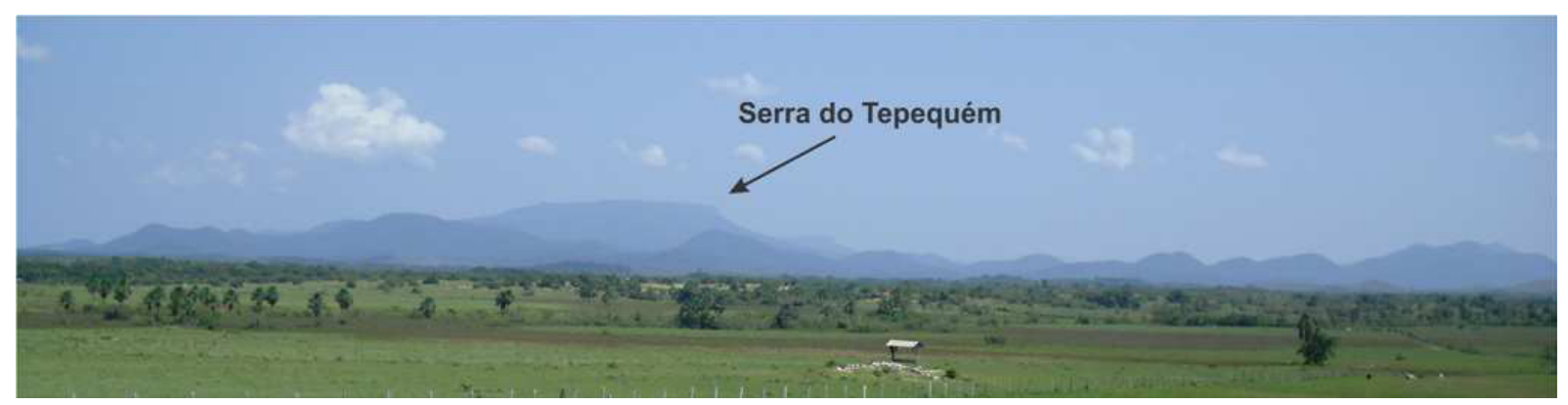

Figura 2: vista da Serra do Tepequém. Figure 2: View of Serra do Tepequém.

Fonte: Nascimento ( 2012). Source: Nascimento ( 2012) 
Arantes, E.C.; Araújo, S.B.; Ferko, G.P.S.; Nogueira, E.M.
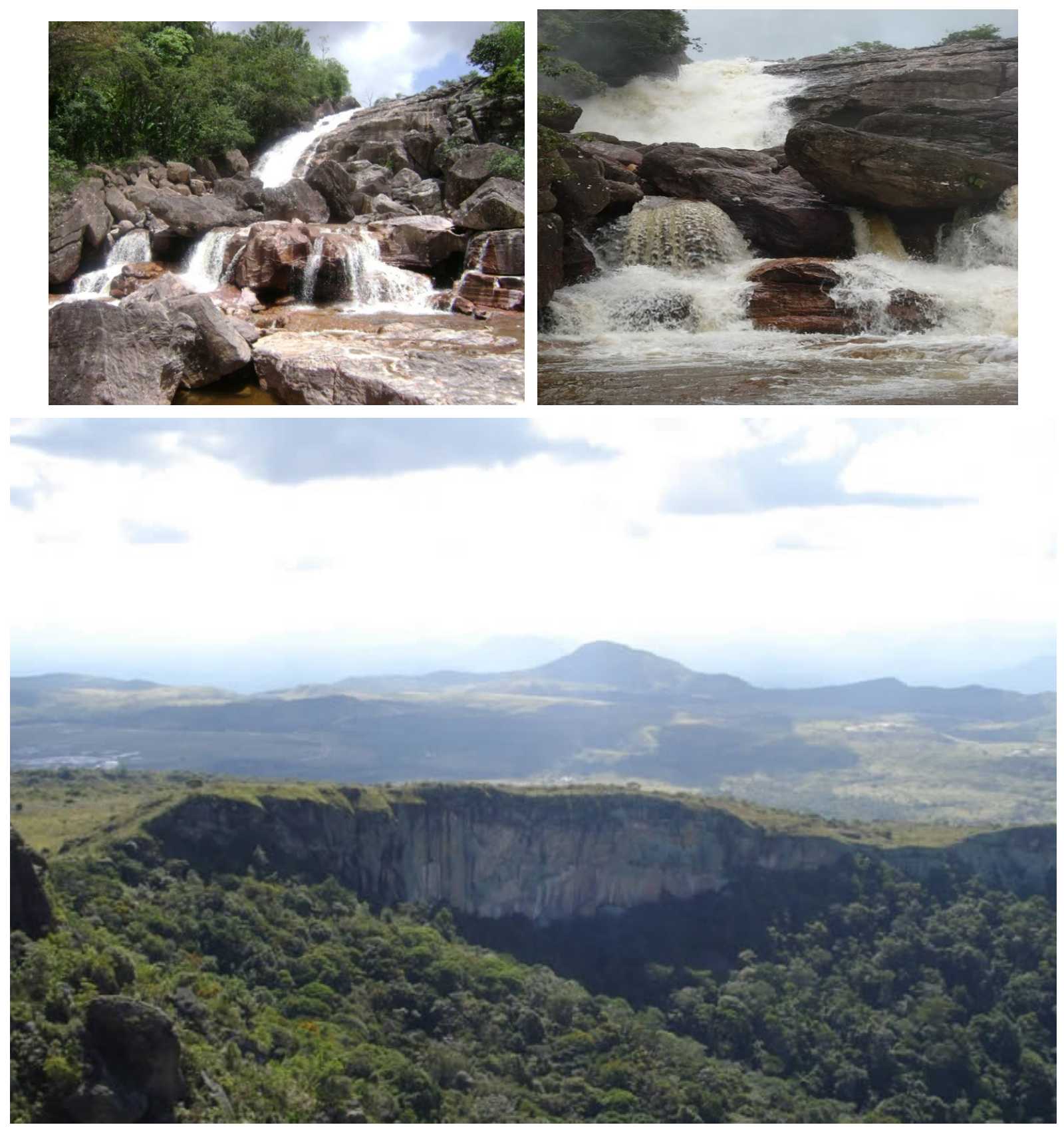

Figura 3: Imagens da Serra do Tepequém. Figure 3: Images of the Serra do Tepequém. Fonte: Portal da Amazônia. Souce: Portal da Amazônia.

Neste trabalho buscou conhecer e analisar a percepção de moradores, visitantes, e empresários de pousadas sobre o ecoturismo praticado na região, onde há algumas empresas atuando, em relação às ações socioambientais e operações dessa modalidade. Realizou-se uma pesquisa de opinião com empreendedores de pousada, residentes, e visitantes. 


\section{Coleta de dados e resultados \\ Ótica dos empresários}

Em primeiro momento, tentou-se saber junto aos empresários do setor o que pensam sobre 0 econturismo. Foram entrevistados 4 representantes das pousadas existentes na região, que serão identificados como pousadas A, B, C e D. De acordo com os respondentes, todas possuem infraestrutura básica, que permite o apoio à atividade ecoturística na região, sob a forma de estacionamentos, sanitários e acomodações. No quesito portaria e recepção, apenas a pousada C possui esse tipo de serviço; enquanto que na disponibilidade de restaurante, somente a pousada $B$ desenvolve essa atividade, com disponibilidade de alimentação. As pousadas A e D somente atuam com oferta de acomodações, configuradas como unidades habitacionais, sendo que a pousada $A$ com $10 \mathrm{Uh}$ e 0 empreendimento $\mathrm{D}$ com $03 \mathrm{Uh}$, com pretensões futuras de construir mais $02 \mathrm{Uh}$.

No que tange à abordagem dos impactos ambientais oriundos do fluxo de visitantes na região, as pousadas $A, B$ e $D$ foram unânimes em apontar a presença de lixo, poluição sonora e vandalismo, como sendo pontos negativos. A pousada $C$ não pontuou nenhum tipo de impacto, mas todas revelaram que é bastante importante para negócio manter o controle do número de visitantes à área, justamente para evitar tais transtornos.

Ao tratar dos fatores que podem ser considerados fundamentais para que haja o incremento do ecoturismo na região do Tepequém, as pousadas $A, B, C$, e D consideram necessário que haja maior interesse por parte dos atores envolvidos, ou seja, governo, empresas e sociedade.

Tomou-se ciência que os empresários das pousadas imbuídos do desejo de melhorias em seus negócios, em cooperação com outros empreendedores se reuniram e fundaram recentemente a Associação de Empreendedores em Turismo do Tepequém, justamente por considerarem que somente estando organizados, serão capazes de conseguir alcançar seus objetivos em comum, seja na disponibilidade de telefonia para que os empreendimentos usufruam da comodidade de oferecer o recebimento de cartões de crédito ou simplesmente a construção de escadarias que permitam o fácil acesso às cachoeiras.

Em relação à questão da sustentabilidade, todas as pousadas responderam que, com vistas ao potencial natural da região para desenvolver práticas de ecoturismo, é possível promover atividades sem degradar a natureza, necessitando-se para isso de um prévio estudo e controle constante no decorrer das atividades.

No quesito sobre os atrativos naturais da região, permitindo maior difusão da cultura local, todas as pousadas responderam que concordam plenamente, tanto que, em virtude desses atrativos naturais, alguns eventos são promovidos pelo SESC e pelo próprio município do Amajari, tendo-se como exemplo as corridas de cavalo e festejos locais. 
Quando questionadas sobre possuírem guias ou profissionais capacitados para acompanhar os visitantes em suas atividades, as pousadas $A, C$ e $D$ responderam ter esse tipo de profissional disponível, e quando não possuem de imediato, indicam um guia da comunidade local para o visitante. Somente a pousada B não disponibiliza esse serviço.

\section{Ótica dos Moradores}

A aplicação dos questionários com os moradores locais, precisamente da área urbana no município de Amajari , aconteceu nos meses de setembro e outubro do ano de 2011, com uma amostra de 86 respondentes

Quando perguntado sobre considerar sua cidade ou região atrativa, $88 \%$ dos respondentes afirmaram que sim, e somente $12 \%$ responderam que não a considera atrativa. Também foi perguntado se o morador gosta do desenvolvimento do turismo na cidade ou região onde ele vive. Percebeu-se que $9 \%$ dos respondentes foram indiferentes quanto ao assunto, $21 \%$ afirmaram não gostar do desenvolvimento turístico, e uma expressiva soma de $70 \%$ se declararam de acordo, conforme gráfico 1 , fato esse relevante quando se pretende desenvolver o ecoturismo (Gráfico 1).

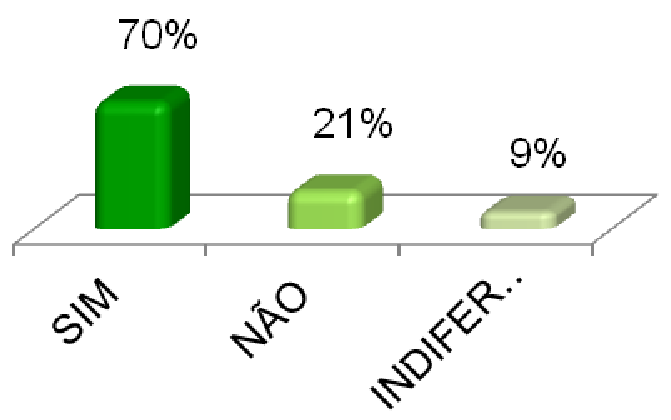

Gráfico 1: Percepção do desenvolvimento da sua cidade ou região relacionado ao turismo. Graph 1: Perception of the development of your city or area related to tourism

No que se refere à valorização da comunidade local, na percepção dos moradores, ficou demonstrado que $95 \%$ dos respondentes se sentem valorizados de alguma forma com a chegada dos turistas, e apenas $5 \%$ se dizem não valorizados.

Quando pesquisados sobre o interesse em trabalhar com turismo/ecoturismo na cidade ou região onde vivem, $53 \%$ dos respondentes afirmaram que sim, enquanto que $47 \%$ responderam que não (Gráfico 2). Esse visível equilíbrio é verificado devido ao fato de boa parte da população local possuir atividades voltadas para o funcionalismo público, para o trabalho com a terra em suas propriedades ou ainda alguns remanescentes da atividade de garimpo. 


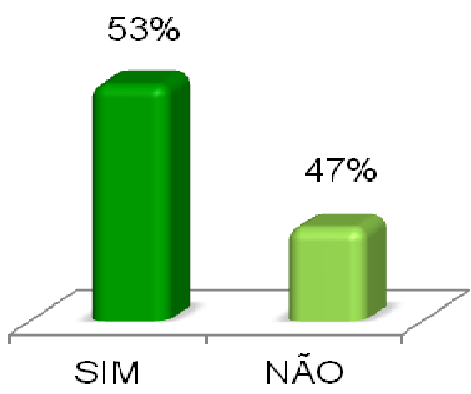

Gráfico 2: Interesse em trabalhar com turismo/ecoturismo na sua cidade ou região. Graph 2: Interest in working with tourism / ecotourism in your city or region.

De acordo com os resultados, $79 \%$ dos respondentes demonstram ter vontade de participar de palestras e reuniões para tratar sobre ecoturismo, e apenas $21 \%$ apresentaram não ter interesse. Quando à vontade de participar de alguma associação relacionada ao ecoturismo, $74 \%$ dos respondentes sinalizaram sim, têm vontade de participar de alguma associação relacionada ao ecoturismo, enquanto somente 26\% não manifestaram interesse.

Também pode ser constatado maior disponibilização de equipamentos turísticos com ações materializadas na criação da Associação de Desenvolvimento Sustentável dos Moradores de Tepequém e na Associação de Empreendedores em Turismo do Tepequém, ambas criadas com o intuito de fomentar e organizar as atividades decorrentes do turismo na região.

O quadro abaixo mostra esta questão e outras do instrumento de coletas de dados e as respostas em termos percentuais:

Dos respondentes, $71 \%$ sinalizaram não perceber nenhum problema ou impactos para a região onde vivem, em decorrência do ecoturismo, no entanto $29 \%$ apontam sim, existir tais problemas e impactos, principalmente na poluição da água, do solo, sonora e visual, abertura de estradas, trilhas e atalhos inadequados (Gráfico 3).

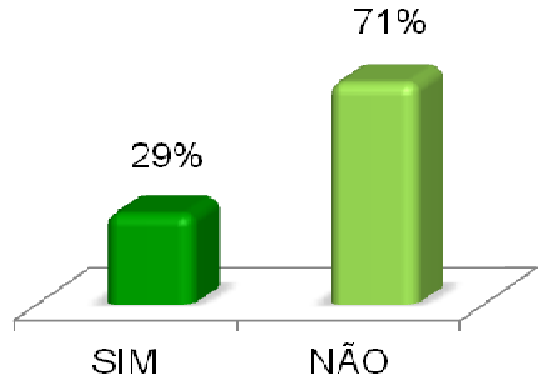

Gráfico 3: Problemas e impactos para cidade ou região.

Graph 3: Issues and impacts to city or region 
Nesse sentido, observou-se, que $92 \%$ dos respondentes acreditam que se houver um maior fluxo de visitantes na região, certamente ocorrerá o desenvolvimento do ecoturismo, gerando renda e promovendo o surgimento de novos negócios. Apenas $8 \%$ responderam que não, que o número de visitantes não exerce influência para o desenvolvimento do ecoturismo.

No intuito de obter informações acerca do envolvimento e conhecimento dos moradores locais sobre o ecoturismo, foi perguntado aos respondentes se o ecoturismo praticado na região está beneficiando os moradores locais e quanto ele acha que sabe ou conhece sobre o assunto. De acordo com as informações, $7 \%$ dos respondentes dizem que ninguém está se beneficiando, $20 \%$ responderam que todos estão se beneficiando, enquanto que $73 \%$ sinalizaram que alguns estão se beneficiando da atividade.

\section{Ótica dos visitantes}

No questionário aplicado aos visitantes, obteve-se o número de 40 respondentes. Em uma das questões abordadas, foi perguntado sobre o costume de visitar o ambiente natural e o meio rural. Como resultado se obteve $90 \%$ dos respondentes sinalizando que sim, dessa forma evidenciando que a região de Tepequém possui demanda para dinamizar a atividade ecoturística. Apenas 10\% sinalizaram que não, que não costumam visitar o ambiente natural e rural, sendo assim visitas esporádicas

No aspecto de acreditar sobre o incremento da atividade ecoturística na região, $100 \%$ dos respondentes foram unânimes, sinalizando que sim. Esse resultado demonstra que as expectativas são positivas e que há o desejo de uma grande maioria com expectativa de que os projetos no segmento do ecoturismo venham a trazer prosperidade para a região.

Em se tratando do envolvimento da população local para o desenvolvimento do ecoturismo, $100 \%$ dos respondentes confirmaram que sim, ser importante o envolvimento da população local, e isso indica que, direta ou indiretamente, a comunidade poderá usufruir dos resultados, principalmente quando da geração de renda, estímulo à preservação do meio ambiente e reforço e valorização da cultura local.

Com relação à figura do profissional guia, foi perguntando ao visitante sobre a contratação do referido profissional para acompanhar nos passeios à região. Somente $20 \%$ dos respondentes afirmaram que sim, haver contratado o guia para acompanhálos nos passeios, e $80 \%$ respondentes sinalizaram que não contrataram nenhum guia. Nesse quesito, com relação ao profissional guia, é interessante salientar que a maioria dos visitantes só contrata o guia quando está em visita pela primeira vez à região, e em um segundo momento, dispensam o serviço por acreditarem possuir conhecimento suficiente sobre a região, o que lhes permite desbravá-la sozinhos, sem auxílio de um profissional.

Associada à questão do guia, foi efetuada a pergunta quanto à avaliação do serviço oferecido. Para tanto, considerou-se os $20 \%$ de respondentes da questão an- 
terior, e como resultado, obteve-se $33 \%$ que avaliaram o serviço como ótimo, $56 \%$ como bom, e 11\% como regular, sem pontuações para as demais avaliações (Gráfico $4)$.

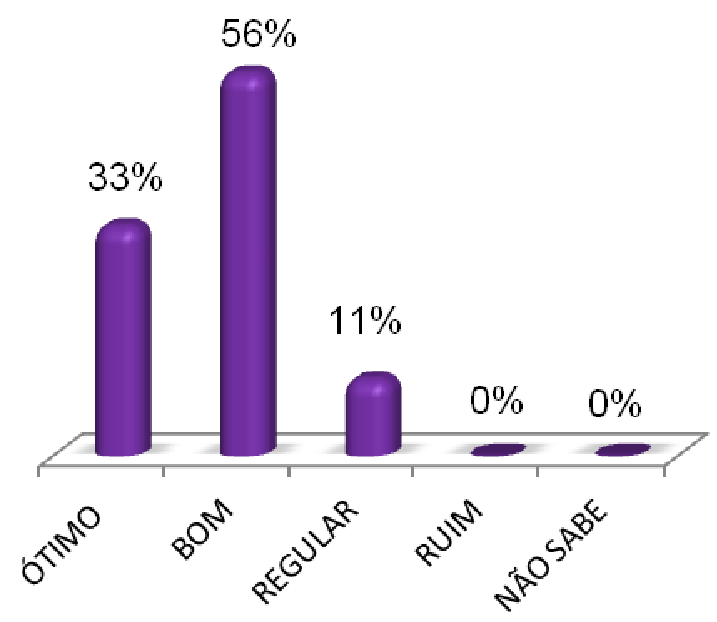

Gráfico 4: Avaliação do serviço de guia.

Graph 3: Evaluation of the service guide.

No aspecto da hospedagem, foi perguntado ao visitante o local onde ficou instalado durante sua visita à região da Serra do Tepequém, $75 \%$ dos respondentes ficaram instalados em pousadas, $0 \%$ em hotel, $0 \%$ em camping, $10 \%$ em casa de amigos, o que é comum, devido a muitas famílias possuírem sítios, chácaras e fazendas na região, e 15\% outro (Gráfico 5). O fato de se ter incluído a variante hotel na pesquisa ocorreu por se acreditar que no município de Amajari pudesse haver algum estabelecimento em atividade, expectativa esta sanada após a aplicação do questionário.

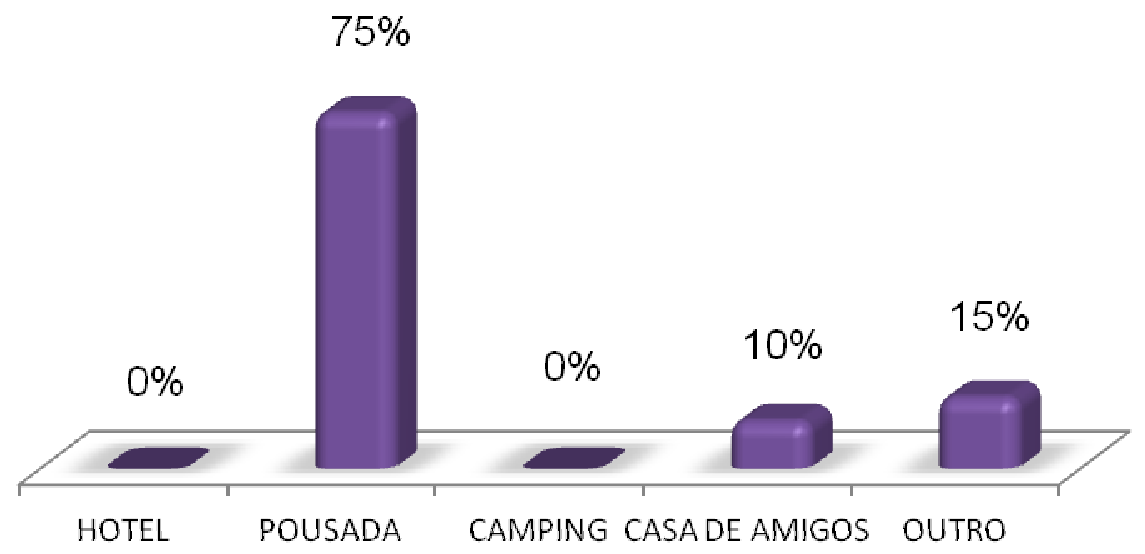

Gráfico 5: Local de hospedagem do visitante. Graph 5: Local of hosting of the visitor. 
Ao longo do desenvolvimento deste trabalho, foi possível observar, em outros estudos sobre o assunto, que a principal ferramenta para detectar as potencialidades ecoturísticas de um determinado lugar é constatar sua vocação natural. Para tanto, foi perguntado ao visitante como ele avalia a diversidade de atrativos existentes na região. Como resultado, teve-se 52,5\% respondentes considerando ótimo, em seguida $42,5 \%$ considerando bom, e apenas $5 \%$ considerando regular os atrativos existentes na região (Gráfico 6).

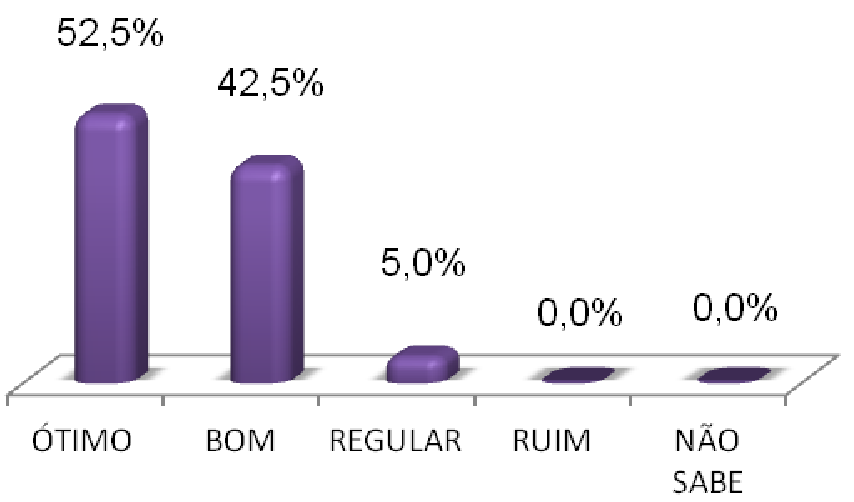

Gráfico 6: Diversidade de atrativos existentes. Graph 6: Diversity of attractive existing.

Outro ponto importante, diz respeito aos preços praticados sobre os serviços oferecidos. Nesse aspecto, foram avaliados de forma generalizada os passeios, atividades e hospedagem. Assim, se obteve $7,5 \%$ que consideram barato os valores cobrados, $72,5 \%$ avaliam como razoável e $20,0 \%$ dos respondentes classificam como caro os preços praticados (Gráfico 7).

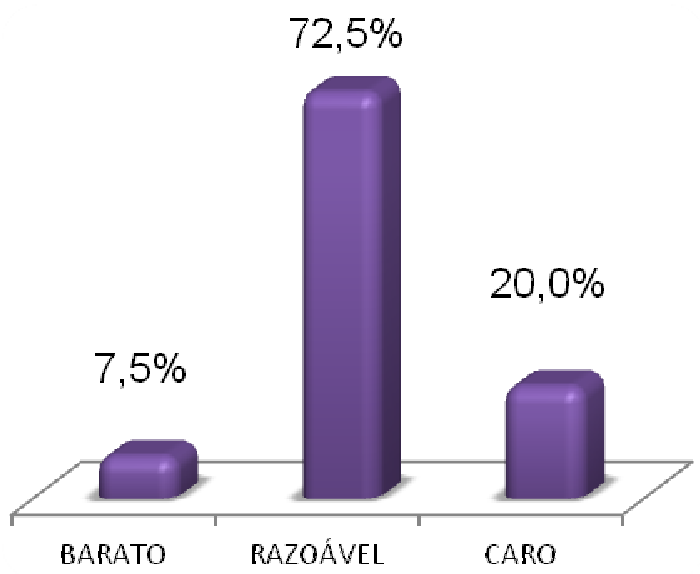

Gráfico 7: Preços cobrados nos serviços. Graph 7: Prices charged by services.

Sob a impressão geral deixada pela região ao visitante, foram obtidos os se- 
guintes resultados: do total de respondentes, $75,0 \%$ sinalizaram como ótimo, enquanto $22,5 \%$ consideram como bom e $2,5 \%$ como regular, evidenciando dessa forma, que apesar de ainda não estar estruturada em sua totalidade, a região desperta o interesse de pessoas em conhecê-la e assim constatar de perto o motivo pelo qual tem sido um dos locais do estado de Roraima que tem conseguido nos últimos anos chamar atenção, devido a sua grande beleza.

Para concluir a etapa de questões direcionadas aos visitantes, Ihes foi perguntado se voltariam à região novamente. Como resultado, obteve-se $95 \%$ dos respondentes sinalizando que sim, que retornaria à região, e apenas $5 \%$ respondentes sinalizou que não (Gráfico 8).

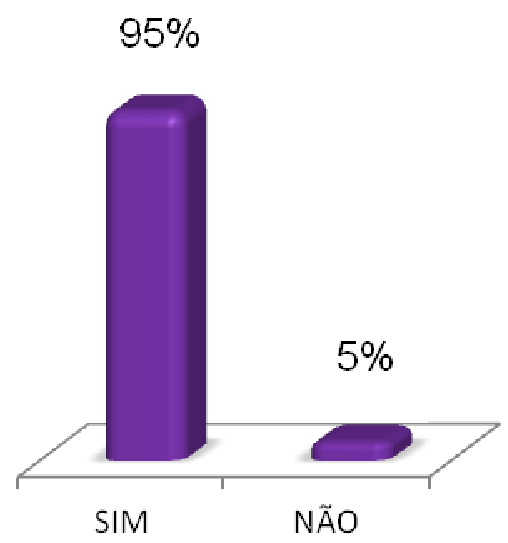

Gráfico 8: Desejo de retornar a região do Tepequém.

Graph 8: Desire to return to the region of the Tepequém

Levando-se em consideração os resultados, aqui demonstrados, nota-se que eles refletem a realidade de um local com grandes possibilidades de, quem sabe num futuro próximo, figurar entre os principais roteiros ecoturísticos da região norte, conforme expectativas de projetos já em andamento, como exemplo o da Rota - 174, que tem como principal objetivo expor para o mercado consumidor de ecoturismo e turismo de aventura, um roteiro integrado com muito verde e belas paisagens do extremo norte do país.

Nesse aspecto, estudos realizados por Mendes et al,(2007) ressaltam a importância de se refletir sobre os desdobramentos evidenciados pelo ecoturismo e dessa forma trazer essas reflexões para as potencialidades existentes em diversas localidades do Estado de Roraima para a prática do mesmo. Ficou evidenciada, mediante a pesquisa, a região de Tepequém/RR, como local propício para diversas práticas que podem ser assim configuradas:

- Tirolesa: prática da travessia de montanhas, vales, lagos ou canyons, por meio de cordas, utilizando uma roldana e equipamentos apropriados. Essa modalidade de esporte radical é muito difundida no mundo inteiro; 
- Cavalgada: Tipo de atividade onde se realiza percursos em meio a natureza. É o tipo de atividade especialmente indicada para terrenos acidentados ou onde o tráfego de veículos não seja possível ou permitido;

- Passeios a pé em veredas: caracterizado por caminhas leves, de baixo impacto, no entanto Tepequém propicia ao ecoturista mais radical, opções de caminhadas com maior grau de dificuldade;

- Observação de aves: é o passeio ecoturístico que tem por objetivo observar as aves em seu habitat natural, sem interferir no seu comportamento ou ambiente;

- Cicloturismo: é uma modalidade onde a bicicleta é o meio de transporte utilizado para percorrer trilhas destinadas à esta atividade;

- Observação de fauna e flora: caracterizada pela observação de animais e plantas em seu habitat natural, frequentemente com um roteiro ou para pesquisa cientifica;

- Estudos do meio ambiente: é a realização de estudos na área que se está percorrendo, sobre as rochas, vegetações, águas, etc. O ideal é que esse tipo de atividade seja acompanhada por um guia, que poderá indicar áreas para pesquisa no local visitado;

- Trekking: é uma atividade de trilhas ou caminhadas, de mais de um dia de duração, por áreas natuarais com relevante beleza cênica, geralmente com incursões em áreas montanhosas.

A tiroleza, o cicloturismo, o trekking, a observação de pássaros, a realização de estudos no meio ambiente, a cavalganda que é uma atividade plenamente viável de se inserir face à paisagem e peculiaridade do terreno. Enfim, todos esses produtos podem ser organizados e gerenciados de tal modo que possibilitem trazer significativos benefícios à região, como indução a pequenos negócios locais, geração de emprego no interior, melhoria na infraestrutura e a preservação do patrimônio natural e cultural do lugar.

\section{Considerações finais}

A Serra do Tepequém vem se destacando por ser um dos principais destinos turísticos, perto da capital do cstado, recebendo vários visitantes. A atividade turística no destino vem se desenvolvendo ao longo da década de noventa, sendo atualmente um dos principais setores de fomento para a economia local, embora tenha atividade pecuária em ascensão. Desde que fora identificada a potencialidade da região para o turismo, novas empresas foram atraídas para o município, tais como: pousadas, restaurantes e outros equipamentos turísticos que foram sendo disponiblizadso para o atendimento da crescente demanda. 
$\mathrm{Na}$ percepção, da maior parte dos turistas, o destino encanta pelas belezas naturais, e a qualidade nos serviços prestados para os entrevistados é boa, entretanto, pode ser melhorada.

Em relação aos preços, passeios e hospedagem são caracterizados como razoáveis. Entretanto, quando os turistas são questionados a respeito do nível de satisfação em relação à região, a maior parte deles está satisfeita e pretende voltar.

A análise das percepções e atitudes dos residentes tem sido efetuada pela preocupação relacionada aos aspectos negativos que o turismo pode desencadear nas localidades receptoras e pelos aspectos positivos que podem ser potencializados. Os resultados parecem apontar para a satisfação relacionada aos benefícios econômicos gerados pelo ecoturismo.

Também é possível observar a percepção positiva a respeito dos benefícios culturais e da influência do turismo na cultura local, uma vez que existe uma agenda de eventos culturais. Entretanto, fatores negativos apontados foram com relação ao meio ambiente, na ótica dos entrevistados.

As análises e conclusões sobre o cruzamento das variáveis relacionadas às potencialidades do turismo na região demonstram que tanto os visitantes, empresários e residentes apreciam a atividade turística e querem o seu desenvolvimento.

Considera-se, ainda, que há necessidade de ações de planejamento turístico. O turismo na região nasceu da ação coletiva da iniciativa privada e de poder público, mas não se pode deixar de considerar que a iniciativa privada foi muito forte e empreendedora, nesse caso.

Diante dos resultados, observa-se a necessidade de um constante aperfeiçamento do serviço turístico prestado ao visitante, e com maior preocupação com a comunidade local. Assim, o planejamento da atividade turística no município, bem como a articulação e colaboração entreos agentes envolvidos no turismo, garantirá a vitalidade do destino, bem como a proteção ambiental.

\section{Referências bibliográficas}

AZEVEDO, L. L. Ecoturismo de grupos indígenas: Experiências Sustentáveis? Tese de Doutorado - Pós-Graduação Interdisciplinar em Desenvolvimento Sustentável do Trópico Úmido, Belém: NAEA/UFPA, 2005.

BARROS, A. J. P.; LEHFELD, N. A.S. Projeto de Pesquisa: Propostas metodológicas. 18 ed. Petrópolis, RJ: Vozes, 2009.

BESERRA NETA, L. C.; COSTA, M. L.; BORGES, M. S. A planície intermontanaTepequém, Roraima, e sua vulnerabilidade erosiva. In: ROSA-COSTA, L. T. ; KLEIN, E. L.; VIGLIO, E. P. (Eds.) Contribuições à Geologia da Amazônia. Belém: SBG - Núcleo Norte, v.5, 2007. pp.89-100. 
BRASIL. Diretrizes para uma Política Nacional de Ecoturismo. Silvio Magalhães Barros II e Denise Hamú M. de La Penha (Coord). Brasília: EMBRATUR. 1994.

CAMPOS, M. D. Etnociência ou etnografia de sabers, técnicas e praticas? In: AMOROSO, M. C.; MING, L. C. \& SILVA, S. M. P. (orgs.) Métodos de coleta e análise de dados em etnobiologia, etnoecologia e disciplinas correlatadas. Rio Claro, UNESP/ CNPQ, 2002.

DIAS, R. Turismo sustentável e meio ambiente. 1. Ed. 3a reimpressão. - São Paulo: Atlas 2007.

FARIA, I. F. Ecoturismo Indígena: Território, Sustentabilidade, Multiculturalismo. São Paulo: Annablume 2012.

GIL, A. C. Como elaborar projetos de pesquisa. 5a Edição. - São Paulo: Altas, 2010.

HANAI, F. Y. Sistema de Indicadores de Sustentabilidade: Uma aplicação ao contexto de desenvolvimento do turismo na região de Bueno Brandão, Estado de Minas Gerais, Brasil. São Carlos. Tese de Doutorado. ESSC/USP. São Paulo, 2009.

HINTZE, H. C. Ecoturismo na cultura de consumo: possibilidade de educação ambiental ou espetáculo? Piracicaba. Dissertação de Mestrado. Escola Superior de AgricuItura/USP, 2008.

IBGE - INSTITUTO BRASILEIRO DE GEOGRAFIA E ESTATÍSTICA (2011). Banco de Dados-Cidades@. Sinopse do Censo 2010. Disponível em: http:// www.ibge.gov.br/cidadesat/link. Php?Uf=RR. Acesso em: 09 out. 2011.

LAKATOS,E. M.; MARCONI, M. A. Fundamentos de metodologia científica.7. ed. São Paulo: Atlas, 2010.

MENDES, A. M. S. et al Ecoturismo, Preservação e Desenvolvimento Local: Algumas considerações. Acta Geográfica - [online].2007,nำ2.ISSN 1980-5772.

MUNHOZ, A. N. R. Ecoturismo, Políticas Públicas e Planejamento Participativo e Comunitário no Município de Presidente Figueiredo, no Estado do Amazonas. Manaus. Dissertação de Mestrado. Programa de Pós-Graduação em Ciências do Meio Ambiente e Sustentabilidade na Amazônia. Universidade Federal do Amazonas, 2010.

NASCIMENTO, F. A. TAVARES JÚNIOR, S. S; BESERRA NETA L. C. Estudo do Compartimentos Geomorfológicos na Serra do Tepequém - RR, através de fotointerpretação em imagens de sensores remotos e produtos integrados via IHS. Revista Geonorte, Edição Especial, V.2, N.4, 2012, p.1464 - 1474.

NETO, J. C. F. Ecoturismo no Litoral do Paraná: Caminhos e Descaminhos. Curitiba. Tese de Doutorado em Meio Ambiente e Desenvolvimento. Universidade Federal do Paraná, 2007.

REVISTA ROTA DOS 15 PONTOS Ano 1,nำ1,jul, 2010. 
RICHARDSON, R. J. et al. Pesquisa social: métodos e técnicas. $3^{\mathrm{a}}$ ed. revista e ampliada. São Paulo: Atlas, 1999. 334 p.

RORAIMA.-Secretaria de Estado de Planejamento e Desenvolvimento. CGEES. In RORAIMA. InformaçõesSocioeconômicas de Amajari/Roraima-2010 . Disponível em:<http://www.seplan.rr.gov.br/roraimaemnumeros/dados municipios/Amajari.pdf>. Acesso em:19 out.2010.

SANTOS, G. E. O. Cálculo Amostral: Calculadora on-line. Disponível em $<\underline{\text { http:// }}$ www.glaubersantos.com/calculoamostral.html>. Acesso: 05 nov. 2011

WESTERN, D. Definindo ecoturismo. In: LINDBERG, K; HAWKINS, D.E. Ecoturismo: um guia para planejamento e gestão. São Paulo: Editora SENAC, 1995.

Emerson Clayton Arantes: Universidade Federal de Roraima, Boa Vista, RR, Brasil.

Email: emersonclaytonarantes@gmail.com

Link para o currículo Lattes: http://lattes.cnpq.br/3222349800613241

Simone Briglia de Araújo: Universidade Federal de Roraima, Boa Vista, RR, Brasil.

Email: simonearaujo@hotmail.com

Link para o currículo Lattes: http://lattes.cnpq.br/7205204167097633

Georgia Patrícia da Silva Ferko: Universidade Federal de Roraima, Boa Vista, RR, Brasil.

Email: geoufpe@yahoo.com.br

Link para o currículo Lattes: http://lattes.cnpq.br/8762583706265854

Elizabete Melo Nogueira: Instituto Federal de Educação, Ciência e Tecnologia de Roraima, Boa Vista, RR, Brasil.

Email: betemnogueira@gmail.com

Link para o currículo Lattes: http://lattes.cnpq.br/7571793745280814

Data de submissão: 29 de junho de 2013

Data de recebimento de correções: 29 de junho de 2013

Data do aceite: 01 de setembro de 2013

Avaliado anonimamente 